\title{
EDUCAÇÃO, PREVENÇÃO E DROGAS: RESULTADOS E DESDOBRAMENTOS DA AVALIAÇÃO DE UM JOGO EDUCATIVO
}

\author{
Simone SouZa Monteiro* \\ Eliane Portes Vargas \\ Sandra Monteiro Rebello
}

\begin{abstract}
RESUMO: Este artigo apresenta os resultados da avaliação do "Jogo da Onda", um jogo sobre a prevenção contra HIV/AIDS e uso de drogas, desenvolvido pela Fundação Oswaldo Cruz. Informado por uma abordagem qualitativa (grupo focal, observação direta do uso do jogo e questionário), o estudo analisa a opinião de 62 estudantes e 17 educadores da rede pública de ensino (Rio de Janeiro/Brasil) sobre o uso do jogo e as temáticas tratadas no material. Para os estudantes e educadores o jogo gera informação, estimula a reflexão e o diálogo acerca de situações do cotidiano relacionadas ao uso de drogas. A visão dos jovens acerca dos temas do jogo aponta para a relevância da percepção do usuário na avaliação do alcance das mensagens veiculadas em recursos de educação em saúde. Os resultados do estudo motivaram o desenvolvimento e a avaliação de novos conteúdos, principalmente sobre saúde reprodutiva e relações de gênero, que irão integrar as edições futuras do "Jogo da Onda". Os novos conteúdos privilegiam as interfaces entre os desafios enfrentados pela juventude na atualidade: epidemia de HIV/AIDS, DST, consumo de drogas lícitas e ilícitas, iniciação sexual, gravidez não-planejada, entre outros.
\end{abstract}

Palavras-chave: Drogas. HIV/AIDS. Educação. Avaliação. Tecnologia educacional.

EDUCATION, PREVENTION AND DRUGS:

RESULTS AND UNFOLDING OF THE EVALUATION OF AN EDUCATIONAL GAME

ABSTRACT: This paper presents the results of the evaluation of the "Jogo da Onda", which deals with drug abuse and HIV/AIDS prevention,

Pesquisadoras do Laboratório de Educação em Ambiente e Saúde, do Departamento de Biologia do Instituto Oswaldo Cruz, da Fundação Oswaldo Cruz (Fiocruz). E-mail: msimone@ioc.fiocruz.br/epvargas@ioc.fiocruz.br

Educ. Soc., Campinas, vol. 24, n. 83, p. 659-678, agosto 2003

Disponível em <http://www.cedes.unicamp.br> 
and was developed by the Fundação Oswaldo Cruz. Based on a qualitative approach (focus group, direct observation of game sets and questionnaires), the text analyzes the opinion of 62 students and 17 teachers of public schools (Rio de Janeiro/Brazil) on the game and its topics. According to those students and teachers, it provides information, stimulates thinking and fosters the discussion on daily situations related to drug use. The students' view on the topics approached by the game suggests the users' perception relevance in evaluating the reach of messages transmitted by educational resources. Based on the results of the study, new contents, especially on reproductive health and gender relationships, were developed and evaluated. They will be incorporated in the forthcoming editions of the "Jogo da Onda". These new contents emphasize the interface between the different challenges faced by youth nowadays such as AIDS, STD, illicit and licit drug use, sexual initiation, and unplanned pregnancy, among others.

Key words: Drug. HIV/AIDs. Education. Evaluation. Educational technology.

\section{Apresentação}

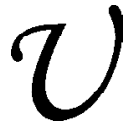

$m$ dos eixos centrais das ações da Informação, Educação e Comunicação (IEC) na área da prevenção contra DST/AIDS centrase na produção e no uso dos chamados materiais educativos, visando à difusão de informações e à promoção de mudanças comportamentais. Diversos profissionais dos campos da educação e da saúde compartilham da idéia de que os denominados materiais educativos se constituem em elementos facilitadores e suportes complementares à prática educativa/pedagógica. Todavia, por meio de uma revisão bibliográfica preliminar (Monteiro et al., 2001), identifica-se que existem poucos estudos acerca das repercussôes da utilização desses materiais. Quer dizer, embora haja o reconhecimento da relevância da produção de recursos educativos/pedagógicos na área da saúde, pondera-se ser necessário refletir sobre suas qualidades e repercussões, levando em conta o ponto de vista não só dos produtores, mas também dos usuários do amplo acervo de materiais produzidos no âmbito da prevenção contra DST/AIDS.

Com o propósito de contribuir para as reflexões acerca do uso de tecnologias educacionais ${ }^{1}$ no campo da saúde, o presente trabalho tem por objetivo apresentar os resultados e os desdobramentos da avaliação do Jogo da Onda (Fiocruz/Consultor, 1998) no contexto escolar. Projetado para ser jogado em dupla, esse jogo ${ }^{2}$ aborda temas rela- 
cionados ao uso de drogas, tais como: conceitos e efeitos de drogas lícitas e ilícitas; legislação brasileira, políticas preventivas, relacionamento familiar e amoroso, práticas sexuais, conflitos pessoais, AIDS, pressão social do grupo, entre outros. Tais temáticas são tratadas por meio da divulgação de conceitos e mensagens, bem como de perguntas e respostas referidas a situações do cotidiano que estão vinculadas, direta ou indiretamente, ao consumo de drogas.

Dada a relevância da percepção do usuário na avaliação do alcance das mensagens veiculadas nos chamados materiais educativos, a primeira parte do trabalho centra-se na análise dos dados sobre a observação do uso do Jogo da Onda entre um grupo de escolares da rede de ensino pública do Rio de Janeiro. ${ }^{3}$ Nessa ocasião buscou-se identificar em que medida o jogo estimula a troca de experiências, a aquisição de conhecimento e a reflexão de temas tratados no material. Com base nos resultados colhidos identificou-se a pertinência de se aperfeiçoar o jogo por meio da ampliação de seus conteúdos, sem alterar a sua dinâmica. No presente artigo também será descrita a segunda fase do estudo, caracterizada pelo desenvolvimento e pela avaliação dos novos conteúdos a serem inseridos no Jogo da Onda.

Convém esclarecer que o estudo aqui descrito integra uma das linhas de investigação do Laboratório de Educação em Ambiente e Saúde (LEAS) ${ }^{4}$ da Fundação Oswaldo Cruz (Fiocruz) sobre DST/AIDS, saúde reprodutiva, sexualidade e drogas, caracterizada pelo desenvolvimento de jogos sobre educação em saúde e investigações acerca das repercussões do uso desses jogos em contexto educativo. Esta vertente de pesquisa também contempla a organização e análise de um acervo de publicações (folheto/folder, manual, catálogo) que visa a orientar futuras políticas na área de Informação, Educação e Comunicação (IEC). ${ }^{5}$

\section{Drogas, educação e tecnologia educacional}

Diversos estudos, nacionais e internacionais, indicam que os programas voltados para a prevenção contra o uso abusivo de drogas devem abordar a dimensão socioeconômica e política deste fenômeno, assim como as representações e práticas da população relativas aos diversos aspectos desse tema. Apoiados na contextualização histórica do fenômeno das drogas, tais análises assinalam o fracasso das políticas de prevenção centradas apenas na repressão e a necessidade de se propor visôes alternativas (Bucher, 1992; Inem \& Acselrad, 
1993; Bastos, 1995). Dentro desse ponto de vista, a abordagem da "redução de danos" ganha destaque. Contraposta à política repressiva de "guerra às drogas", tal vertente tem por base dois pressupostos: o precedente histórico da inexistência de sociedades que tenham prescindido do uso de psicoativos; e que tais usos determinem o mínimo de danos e o máximo de alívio e bem-estar a indivíduos e comunidades. Salienta-se assim a importância de se avaliarem os danos que se quer evitar, entre outros aqueles causados pelo consumo de psicoativos, procedendo a uma classificação e hierarquização exaustiva desses danos. Para tal considera-se ser prioritária a ação educativa preventiva ao uso indevido de drogas, ainda que isso não signifique operar com a dicotomia preventivo versus curativo (Camargo Jr., 1999). ${ }^{6}$ Enfatiza-se aqui o importante papel dos sistemas públicos de educação e de saúde nessas ações (Ministério da Saúde, 1999).

Vale destacar que, conforme descrito por Monteiro \& Rebello (2000), o desenvolvimento do Jogo da Onda foi norteado pelas análises críticas das políticas repressivas, assim como pelas restriçōes ao predomínio de um padrão definido pelo modelo biomédico que ainda prevalece nas ações de educação em saúde. Segundo Stotz (1993) a hegemonia do saber biomédico nas práticas de educação em saúde ganha força principalmente no campo da medicina preventiva, por incutir normas e padrões de comportamento com ênfase no indivíduo, formas adequadas de higiene, mudanças de hábitos e atitudes pela via estrita da informação. Todavia, identificam-se várias críticas a esse modelo que se apóiam, entre outros aspectos, nas evidências epidemiológicas sobre as relações entre melhorias de saúde e fatores sociais, comportamentais e ambientais.

Ao valorizar a dimensão sociocultural e política do processo educativo, destacando as experiências e opinióes dos educandos relacionadas ao uso de drogas e temas afins, o referido jogo procura incorporar uma determinada visão crítica da educação no campo da saúde, conforme indicam os estudos de Borges (1996), Melo (1993) e Oshiro (1988), para citar alguns. Nessas análises a educação em saúde é concebida como um "campo de práticas que se dão no nível das relaçôes sociais” (L'Abbate, 1994), estabelecidas entre profissionais de saúde, as instituições e, sobretudo, o usuário no cotidiano das atividades no serviço de saúde, sendo determinada histórica e socialmente. Como um dos pressupostos dessa abordagem crítica, tem-se a valorização do processo de capacitação dos indivíduos e de grupos 
para a transformação da realidade, em substituição à persuasão sobre os riscos de doença e agravo à saúde ou à transferência de informação.

Levando em conta o exposto, grosso modo, pode-se dizer que é na crítica ao modelo hegemônico tradicional de abordagem da saúde que tem emergido novas perspectivas pedagógicas. Estas tendem a conferir privilégio aos espaços coletivos e a enfatizar a necessidade de se reconhecer o caráter histórico e os condicionantes sociais, políticos e econômicos do processo saúde/doença, propondo a formação de uma consciência crítica voltada à transformação da realidade social.

A contextualização dos fundamentos educacionais que orientaram a produção do Jogo da Onda objetiva chamar a atenção para a relevância da reflexão sobre o uso de tecnologias educacionais aplicadas à saúde, com vistas à disseminação de conhecimentos sobre saúde e doença em contexto educativo. Tal enfoque tem por base a reduzida problematização dos usos e efeitos dos chamados materiais educativos, no âmbito nacional, ainda que se possa reconhecer algumas iniciativas que vêm contribuindo para a acumulação de conhecimento nesse campo (Monteiro et al., 2001). Nesta direção convém citar que as análises de Vargas \& Siqueira (1999), acerca dos discursos subjacentes às imagens do corpo sexual e reprodutivo veiculadas em vídeos educativos, revelam a existência de um amplo espectro teórico-conceitual que informa a produção de recursos tecnológicos e as intervençóes educativas. Tal diversidade sugere que diferentes perspectivas teóricas orientam o desenvolvimento de materiais e indica a necessidade de um maior aprofundamento, capaz de dar suporte à elaboração, análise e avaliação dos usos desses recursos em contexto educativo.

Reflexões sobre a importância do processo de avaliação de ações educativas $^{7}$ apontam para a concomitante complexidade e viabilidade de tal tarefa, bem como para as suas contribuições na identificação de indicadores de impacto e na reorientação das ações de educação em saúde. Para efeito deste trabalho não se teve a intenção de proceder a uma avaliação dos programas educativos ${ }^{8}$ na área em questão. Todavia, deve-se levar em conta que a investigação sobre as repercussões do uso de materiais, aqui proposta, pode se constituir em uma medida indireta da avaliação de programas e subsidiar ações de educação e comunicação em saúde. A avaliação do uso de materiais, centrada no ponto de vista do usuário, permite a sua adequação e o aperfeiçoamento. A partir desse enfoque, pondera-se que não se deve perder de vista a diversidade das experiências e os valores dos grupos aos quais os recursos se destinam. 
O debate sobre a necessidade de adequação das proposições educativas ao contexto sociocultural dos educandos não é novo, seja no contexto escolar ou da saúde. O trabalho de Lefevre (1980) sobre os cartazes dos escolares a respeito da esquistossomose oferece uma interessante contribuição, ao afirmar que somente conteúdos que reflitam de perto a cultura dos educandos têm possibilidades de provocar nestes mudanças de comportamento. Segundo o autor, a abordagem escolar acerca desta temática não levou em conta as experiências de vida e os valores dos estudantes.

Enfim, destaca-se que as ações e investigações sobre tecnologias educacionais aplicadas à saúde devem enfrentar alguns desafios. Entre eles, avançar teoricamente nas análises sobre a produção e o uso de materiais educativos e suas relações com as concepçôes educativas preventivas que os norteiam e, dessa forma, orientar futuras ações de educação e comunicação em saúde. Por meio da descrição da avaliação do uso de um jogo educativo, o presente trabalho visa a contribuir para as reflexôes sobre abordagens educativas e o uso da tecnologia educacional na área da saúde.

\section{Metodologia}

Estudos acerca do uso de métodos qualitativos no campo das Ciências Sociais e áreas afins (Blanchet \& Gotman, 1992; Becker, 1994; Marshall \& Rossman, 1995) sugerem que os fundamentos da pesquisa norteiem a escolha da metodologia e o instrumental utilizado para a análise dos dados. No presente trabalho a metodologia utilizada foi composta de duas fases: a primeira centrada na análise do uso do Jogo da Onda entre um grupo de escolares da rede de ensino pública do Rio de Janeiro; a segunda pelo desenvolvimento e pela avaliação dos novos conteúdos a serem inseridos no Jogo da Onda.

Os procedimentos metodológicos adotados foram complementares. A primeira fase caracterizou-se pela realização de grupos focais, observação direta das partidas, com e sem a presença de um professor, e aplicação de questionário após a partida do jogo. Participaram dessa fase 62 jovens, entre 12 e 18 anos, de ambos os sexos, matriculados na $8^{a}$ série e no $1^{\circ}$ ano do $2^{\circ}$ grau, de 4 estabelecimentos de ensino da rede de ensino pública do Rio de Janeiro," que não haviam jogado o Jogo da Onda. Cabe informar que, além dos 4 professores, também responderam ao questionário sobre o jogo 13 educadores inseridos em programas de prevenção, ${ }^{10}$ totalizando 17 opiniões. 
A partir da análise da avaliação do uso do Jogo da Onda constatou-se que alguns assuntos não enfatizados no jogo foram destacados pelos jovens como uma referência significativa na discussão dos temas. Com base nessas evidências e na revisão bibliográfica, foi realizada a segunda fase do trabalho, constituída pelo desenvolvimento de 60 novas cartas, enfocando as interfaces entre os conteúdos abordados no jogo e demais temas da adolescência, principalmente saúde reprodutiva e relaçóes de gênero. As novas cartas criadas foram testadas mediante novas observaçôes do uso do jogo e aplicação de questionários em um grupo de 50 alunos da rede pública e privada do Rio de Janeiro, de ambos os sexos e na faixa etária de 13 a 18 anos. Tais cartas foram remetidas a 3 consultores para apreciação quanto à adequação da linguagem, clareza das idéias e exatidão/correção das informaçôes. Vale destacar que ao elaborar as cartas não houve alteração da dinâmica do jogo, ou seja, as cartas criadas foram incorporadas aos baralhos já existentes.

Descritas as duas fases que compóem a metodologia utilizada, cabem algumas ponderaçôes acerca dos procedimentos adotados. De acordo com Dawson e colaboradores (1992, p. 3-4) a técnica do grupo focal ${ }^{11}$ compreende uma discussão em grupo em torno de um tema específico, entre pessoas que compartilham de características e/ ou experiências comuns. $\mathrm{O}$ uso dessa técnica nas pesquisas científicas permite lançar luzes sobre as opiniōes, crenças e práticas de um grupo social, bem como orientar a formulação das hipóteses e do desenho de um projeto. Dentro de um ponto de vista complementar, Soares (1997) destaca a utilização de grupos focais na abordagem qualitativa de pesquisa em educação em saúde, planejamento de programas, avaliação processual e de resultados. Segundo a autora, sua importância reside em seu potencial de "gerar hipóteses, descobrir percepções e atitudes de pequenos grupos, obter informaçóes e estimular novas idéias" (1997, p. 117).

Os grupos focais, realizados na primeira fase, caracterizaram-se por reunirem jovens que têm em comum a faixa etária e o fato de pertencerem à rede pública de ensino do Rio de Janeiro. Com base em um roteiro, foram discutidos os seguintes temas: conceitos e efeitos das drogas; motivaçôes para o consumo; visão acerca do usuário de drogas; uso de drogas e relações familiares/afetivas; drogas e AIDS, prevenção; pressão social/dificuldades na vida cotidiana; drogas e legislação. As sessōes foram coordenadas por uma pesquisadora (com formação em psicoterapia) e observadas por uma segunda pesquisadora 
(com formação em educação em saúde). Para minimizar as possíveis dificuldades de se abordar assuntos relacionados a consumo e/ou tráfico de drogas e práticas sexuais, ${ }^{12}$ foi ressaltado o compromisso com o anonimato dos depoimentos e a relação de confiança e credibilidade. Com duração média de uma hora e quinze minutos, os encontros foram gravados com o consentimento dos escolares. A utilização do grupo focal permitiu a identificação da visão dos(as) alunos(as) sobre o Jogo da Onda, bem como de demais trabalhos no campo da prevenção contra HIV/AIDS e uso indevido de drogas. Ademais, representou uma fonte de informação privilegiada acerca dos significados atribuídos pelos(as) jovens aos temas relativos ao consumo de drogas, citados anteriormente. Pode-se observar que, além de cumprir a finalidade de instrumento de pesquisa, constituiu-se em um meio de reflexão para os participantes. Os(as) escolares, em geral, manifestaram interesse e disponibilidade para relatar suas experiências; agradeceram a oportunidade oferecida e reiteraram o desejo de participar de situações semelhantes, capazes de propiciar o diálogo e a interação.

A observação direta das partidas com grupos de alunos(as) permitiu, em ambas as fases, o registro da observação orientado por um roteiro. De acordo com Lopes (1994), a observação direta dos fatos no processo de pesquisa em comunicação social, a partir de situações interativas, permite o registro dos diversos fatores, esperados ou não, que surgem no decorrer da investigação. Na primeira fase, tal estratégia metodológica favoreceu a identificação de diversos aspectos referentes ao contexto de aplicação do jogo, quais sejam: 1) a influência da presença de um educador ou liderança juvenil na partida; 2) a compreensão e o respeito às regras e as adaptaçôes destas; 3) o interesse pela dinâmica de abordagem dos temas e o entendimento do conteúdo do jogo; 4) o entrosamento e a participação dos estudantes e demais fatores relativos à motivação pelo jogo, que serão detalhados posteriormente nos resultados. $\mathrm{Na}$ segunda fase, a observação direta do uso do jogo com as novas cartas elaboradas permitiu registrar as opiniōes dos alunos sobre a compreensão e o conteúdo dessas cartas.

Os questionários dirigidos a alunos(as) permitiram, na primeira fase, coletar dados referentes a: capacidade do jogo de gerar interação e debate, fornecer informação, fomentar a expressão das opiniōes dos participantes e esclarecer dúvidas. Foram ainda registradas as opiniões sobre outros recursos envolvendo o tema da prevenção contra o uso de drogas, bem como críticas e sugestôes com relação ao jogo. $\mathrm{O}$ questionário dirigido para os educadores, além destes temas, 
continha informaçóes sobre o número de vezes em que o jogo foi utilizado, o contexto de aplicação, a faixa etária e o nível de escolaridade do grupo. Na segunda fase, ao final de cada partida, os alunos preencheram questionário individual contendo opiniōes sobre as novas cartas e sugestôes de inclusão de outras questōes.

\section{Resultados}

Neste item serão descritas as opiniōes dos alunos e educadores sobre o jogo, a percepção dos estudantes acerca dos temas abordados no material, bem como os desdobramentos do estudo relativos ao desenvolvimento e à avaliação dos novos conteúdos.

\section{Opiniōes sobre o jogo}

Segundo a opinião dos 62 estudantes e das 17 educadoras, o Jogo da Onda é um recurso capaz de informar, promover a reflexão e estimular o debate acerca de várias situaçôes cotidianas relacionadas ao uso de drogas. Grande parte (79\%) dos(as) alunos(as) atribuiu ao jogo o conceito "muito bom", considerando-o informativo e interativo; $80 \%$ afirmaram que por meio desse material é possível conhecer melhor a opinião dos colegas; cerca de $70 \%$ responderam que pode expressar plenamente suas opiniōes; $98,4 \%$ concordam que o jogo ajuda a compreender temas referentes ao uso de drogas, particularmente os conceitos e efeitos das drogas e sua relação com o contexto familiar; $98,4 \%$ afirmaram que gostariam de jogar novamente.

Foi identificado que os(as) estudantes demonstraram interesse em participar de programas de prevenção contra o uso de drogas. A maior parte deles já teve acesso a informaçóes sobre esta temática por meio de materiais pedagógicos diferenciados (folhetos, vídeos etc.) e de atividades diversas (palestras, encenaçōes, feira de ciências). Entre as atividades pedagógicas experimentadas, as propostas interativas que favorecem o diálogo - como os jogos - foram valorizadas pelos jovens. Por outro lado, as açōes predominantemente informativas foram criticadas. O grupo pesquisado salienta que o enfoque interativo do Jogo da Onda constitui uma das principais qualidades desse material. Tal característica é percebida como essencial à prática pedagógica efetiva, uma vez que propicia a interlocução e a aprendizagem. 
Os dados empíricos convergem com reflexões no campo da educação. A relevância da interatividade - por meio de recursos (dinâmicas e jogos) capazes de estimular a expressão de idéias e o intercâmbio grupal - foi assinalada por Rocco (1999). Cortes (1999), por sua vez, aponta os méritos dos jogos como proposta metodológica pelo fato de tais recursos representarem "o lúdico como fundamento da cultura e de suas formas de transmissão e resgatar[em] o diálogo como lugar de encontro entre os jovens e os educadores" (1999, p. 763). Conclui-se que o uso de materiais lúdicos e interativos propicia a deflagração de um processo cognitivo questionador, favorecendo a reflexão e a aquisição de conhecimento.

Com relação ao contexto de utilização do jogo, observa-se que a potencialização deste está intimamente ligada a determinadas condições de sua aplicação. Notou-se que locais de muita circulação de pessoas tendem a inibir a participação dos estudantes. Tal fato indica que o ambiente de aplicação do jogo interfere no desenvolvimento da partida. A atuação de uma liderança juvenil ou de um educador não é imprescindível, entretanto pode dinamizar (ou não) a partida por meio do estímulo ao debate. O entrosamento do grupo e a predisposição para atuar em equipe também interferem positivamente na dinâmica do jogo. Salienta-se ainda a importância da inserção do material em programas de prevenção. A conjugação dos fatores descritos favorece a participação dos jovens em uma atividade lúdica e competitiva, como o Jogo da Onda.

Vale registrar que, para os profissionais de ensino, o caráter dinâmico dos jogos marca a diferença entre estes e os demais materiais educativos, além de motivar as diversas faixas etárias. Embora $70,6 \%$ tenham revelado não ter dificuldade na aplicação do material, alguns problemas foram apontados, como leitura e compreensão do conteúdo das cartas e das regras. Todavia, essas dificuldades foram superadas com a ajuda de um facilitador, isto é, de um educador ou de um dos jogadores.

\section{Percepção dos jovens sobre os temas abordados no jogo}

Os resultados sobre a visão dos jovens acerca dos temas abordados no Jogo da Onda, aqui descritos sumariamente, ${ }^{13}$ sugerem a relevância da percepção do usuário na avaliação do alcance das mensagens veiculadas em recursos de educação em saúde. Foi possível identificar que a iniciação do jovem no consumo de substâncias 
psicoativas está relacionada a diversos fatores, tais como: curiosidade em experimentar (principalmente álcool e cigarro); vulnerabilidade à pressão social de grupo; desconhecimento dos efeitos das drogas; fácil acesso a estas; não-reconhecimento de que o consumo, mesmo descontínuo, pode levar à dependência química. Colabora ainda para a experimentação a escassez de um diálogo franco acerca do tema em casa e no colégio, embora idealmente a família e a escola sejam vistas como instituições importantes no processo de socialização.

No que se refere ao poder legal e ilegal, notou-se uma clara ausência de confiança na polícia, sendo recorrentes as queixas acerca das suas atitudes de desrespeito e agressividade com relação aos jovens. Algumas das sugestôes do grupo sobre alternativas de reformulação da legislação vigente se aproximam da atual proposta de descriminalização, na qual se retira o ato de consumir drogas da esfera penal, mantendo nessa esfera as atividades de tráfico.

Os jovens pertencentes às regiōes mais próximas do tráfico e de intervenções policiais repressivas têm maior receio em abordar as experiências de violência; em contraste com o relato mais espontâneo daqueles que se apresentam, aparentemente, mais distanciados do comércio ilegal de drogas. Dizemos "aparentemente" pois o uso de drogas lícitas e ilícitas é realidade em todas as localidades que compõem a amostra e grande parte dos(as) alunos(as) convive com familiares que fazem uso abusivo de álcool.

\section{Desdobramentos: desenvolvimento de novos conteúdos}

Com base na avaliação do jogo, observou-se que alguns assuntos, como: DST, masturbação, aborto, fidelidade conjugal, homossexualismo, amor, métodos contraceptivos, gravidez, diferenças entre homens e mulheres, deveriam ser ampliados no material, sem que as regras do jogo fossem alteradas. Assim, com base na observação do uso do jogo, na opinião dos estudantes e na revisão bibliográfica foram criadas novas cartas, relativas principalmente a saúde reprodutiva, relaçôes de gênero e uso de drogas, a serem incorporadas nas ediçôes futuras do Jogo da Onda. Tal perspectiva visa a enfatizar a necessidade de se contemplar nas abordagens educativas as interfaces entre saúde, educação, sexualidade, reprodução e gênero.

Contribuem para esta visão, voltada para a integração das temáticas, as conexões entre relações de gênero e o uso de subs- 
tâncias psicoativas. Estudos assinalam que existem variaçóes relevantes de consumo e tipos de droga entre homens e mulheres. Dados da literatura nacional (Hearst et al., 1999; Bastos \& CarliniCotrim, 1998; Tiba, 1998) informam um predomínio das chamadas drogas "de rua" ou drogas pesadas (maconha, cocaína e inalantes) entre estudantes do sexo masculino; em contrapartida, entre escolares do sexo feminino prevalece o consumo de medicamentos (anfetaminas, ansiolíticos, tabacos e solventes). A recente produção acadêmica internacional, referendada em estudos de prevalência do uso de drogas entre jovens, também sugere diferenças significativas relacionadas ao gênero (Lynskey et al., 1999; Moon et al., 1999; Brook et al., 1998; De Wit et al., 1997; Odgers et al., 1997).

A relevância das questóes relacionadas ao gênero também pode ser identificada em outros campos, como informam as reflexôes sobre a intervenção docente no campo da educação. Giroux (1995), por exemplo, analisa a escola como lugar de dominação e reprodução, chamando a atenção para as marcas deixadas pelas questōes de gênero, de classe e raça no agir e no pensar dos educadores. Investigações indicam ainda as variações de gênero na intervenção docente (Souza, 1999), assim como a necessidade de ser incorporada à abordagem educacional a dimensão sociocultural dos eventos relacionados à saúde sexual e reprodutiva, tais como a gravidez na adolescência (Oliveira, 1998).

Isto posto, cabe destacar que a necessidade de integração das temáticas também tem sido apontada no campo da saúde sexual e reprodutiva, seja em termos de açóes (Diniz \& Villela, 1999), seja em termos da produção de tecnologias educacionais (Monteiro et al., 2001). Tais análises identificam a existência de um grande número de açôes e materiais sobre DST/AIDS, cujo enfoque não contempla a integralidade dos temas sexualidade, gênero, saúde reprodutiva, família, e outros aspectos que interferem na vulnerabilidade individual e social a DST/AIDS.

Alinhado com tais perspectivas, o presente estudo pauta-se na idéia de que os materiais educativos devem ser concebidos como produtos culturais e de comunicação, uma vez que no desenvolvimento e no uso de tais recursos se encontram implicados, por meio de seus conteúdos e/ou formas, entre outros, os elementos estruturantes da identidade social (atributos de classificação do sujeito, tais como estratificação social, idade, gênero etc.). 


\section{Conclusão}

O presente estudo teve por objetivo apresentar os resultados e os desdobramentos da avaliação do Jogo da Onda, a partir do ponto de vista do usuário, isto é, alunos e educadores. Compreende-se que essa proposta permite dimensionar a viabilidade e o alcance de seus objetivos e, dessa forma, contribui para a revisão e atualização dos conteúdos e das abordagens de temas de saúde no âmbito das políticas públicas.

Assinala-se que tal perspectiva deve contemplar a análise dos fundamentos que definem o modo de se conceber os fenômenos educativos de caráter preventivo, possibilitando uma melhor caracterização das interfaces entre os temas tratados. A reflexão sobre a ação educativa pode consistir em uma das vias de superação dos problemas existentes na relação entre a investigação e a formulação de políticas públicas. Bejarano (2000), por exemplo, problematiza que a natureza distinta entre esses dois processos gera tensões nesses campos, ao analisar os desafios da formulação de políticas públicas no enfrentamento da drogadição. No âmbito da educação em saúde, Vasconcelos (1999) também aponta para os conflitos presentes na prática profissional, decorrentes da oscilação entre a intervenção e a compreensão dos fenômenos.

Com objetivo de colaborar nesta direção, ressalta-se com este estudo a importância do desenvolvimento, acompanhado de processos de avaliação, de tecnologias educacionais aplicadas à saúde, uma vez que essas investigaçôes fornecem subsídios para programas preventivos. No caso particular, mediante o estímulo à reflexão e interlocução sobre problemas da atualidade como a epidemia de AIDS, a gravidez não-planejada, o uso de drogas, entre outros. ${ }^{14} \mathrm{De}$ acordo com os resultados descritos, pode-se dizer que o uso de jogos educativos, lúdicos e interativos propicia a deflagração de um processo cognitivo questionador, favorecendo a reflexão e a aquisição do conhecimento, constituindo-se em suporte e incentivo à ação educativa.

Por fim salienta-se que as tecnologias educacionais (jogos, livros, vídeos, entre outros) são instrumentos que complementam, mas não substituem a ação do educador. Neste sentido, é fundamental investir na formação continuada de profissionais das áreas de ensino e saúde, formal e informal. É pertinente informar que as novas cartas, criadas no decorrer do trabalho, foram editadas e distri- 


\section{buídas para os alunos e profissionais envolvidos na testagem e farão parte das futuras edições do Jogo da Onda.}

\section{Recebido em agosto de 2001 e aprovado em maio de 2002.}

\section{Notas}

1. Sobre o conceito de tecnologia educacional ver: Ribinik (2001); Siqueira (1998); Amorim (1998); e Stone (1981).

2. O jogo contém 1 tabuleiro; 1 dado; 4 pinos e 4 baralhos coloridos, bem como um encarte com dicas de atividades e sugestôes bibliográficas.

3. Esta investigação contou com a colaboração de participantes do "Projeto de Prevenção às DST/AIDS e ao abuso de drogas nas escolas públicas estaduais e municipais do Rio de Janeiro" - denominado de "Ser Vivo" -, coordenado pelas secretarias estaduais de Saúde e Educação (RJ) e Municipal de Educação (RJ), e apoiado pela Coordenaçãao Nacional de DST/ AIDS, no período de maio a agosto de 1998.

4. O leas faz parte do Departamento de Biologia do Instituto Oswaldo Cruz.

5. Ver Monteiro et al., 1994; Schall et al., 1999; Vargas \& Siqueira, 1999; Monteiro \& Rebello, 2000; Vargas et al., 2000; Rebello et al., 2001.

6. Esse pressuposto serve de apoio à análise dos benefícios e alcances da abordagem de "redução de danos", tanto nas ações preventivas quanto terapêuticas, que incluem não apenas os usuários em potencial, os experimentadores e os usuários ocasionais, mas também os dependentes químicos. Tais benefícios podem ser ilustrados por avaliaçôes de programas de prevenção no contexto escolar (Soares, 1997) e por análises das políticas de distribuição de seringas para usuários de drogas injetáveis (Mesquita \& Bastos, 1994), respectivamente.

7. Ver Ayres (1996) para avaliações de açôes preventivas no Brasil; ver Gilham \& Sivewright (1997) para avaliação de programas de prevenção contra as drogas na realidade norte-americana.

8. Ver produção voltada à avaliação de programas de prevenção contra as drogas, tais como o número especial da Evaluation Review (Kreft \& Brown, 1998) e Soares (1997).

9. Das quatro unidades de ensino, duas estão localizadas no município de Caxias (contíguo ao município do Rio de Janeiro) e outras duas na Zona Sul do município do Rio de Janeiro.

10. O primeiro momento foi composto pelas seguintes etapas: $1^{\mathrm{a}}$ etapa - grupo focal com 8 alunos(as) antes da aplicação do jogo; $2^{a}$ etapa - observação direta da aplicação do jogo com 8 alunos(as) na presença de um professor, seguida de aplicação de questionários para o professor e os(as) alunos(as); $3^{\text {a }}$ etapa - observação direta da aplicação do jogo com 8 alunos(as) sem o professor, seguida de aplicação de questionário; $4^{\mathrm{a}}$ etapa - grupo focal com 8 alunos(as) depois da aplicação do jogo; $5^{\mathrm{a}}$ etapa - questionário dirigido aos educadores.

11. Coordenada por um moderador, tal estratégia se diferencia da entrevista coletiva na medida em que as questóes não são dirigidas para cada participante individualmente e sim para o debate coletivo.

12. Parker et al. (1991) e Barbosa (1997, p. 65-78) destacam as contribuiçõos do uso da técnica do grupo focal nas investigaçóes sobre cultura sexual. 
13. Para mais informações, ver Rebello et al., 2001.

14. Demais reflexões revelam que tais condiçôes atingem particularmente os segmentos de menor poder aquisitivo. Os dados de Berquó (1998) sobre indicadores da população juvenil do Brasil com relação às condições sociodemográficas, de saúde, educação, trabalho, previdência, cultura e gastos com políticas públicas corroboram essa idéia. Ver ainda Schor et al. (1999).

\section{Referências bibliográficas}

AMORIM, A.C.R. Quais os caminhos a trilhar na discussão da tecnologia educacional no âmbito das escolas? Revista Tecnologia Educacional, Rio de Janeiro, v. 26, n. 141, p. 41-45, abr./jun. 1998.

AYRES, J.R. O jovem que buscamos e o encontro que queremos ter: a vulnerabilidade como eixo de avaliação de açóes preventivas do abuso de drogas, DST/AIDS entre crianças e adolescentes. In: TozZI, D. et al (Org.). Papel da educação na ação preventiva ao abuso de drogas e as DST/AIDS. São Paulo: FDE, 1996.

BARBOSA, R. Negociação sexual ou sexo negociado?: gênero, sexualidade e poder em tempos de AIDS. 1997. Dissertação (Mestrado em Saúde Coletiva) - Instituto de Medicina Social, Universidade do Estado do Rio de Janeiro, Rio de Janeiro.

BASTOS, F.; CARLINI-COTRIM, B. O consumo de substâncias psicoativas entre jovens brasileiros: dados, danos \& algumas propostas. In: Berquó, E. (Org.). Jovens acontecendo na trilha das politicas públicas. Brasília: CNPD, 1998.

BASTOS, I.F. Ruina \& reconstrução: AIDS e drogas injetáveis na cena contemporânea. Rio de Janeiro: Relume-Dumará, 1995.

BECKER, H. Métodos de pesquisa em ciências sociais. São Paulo: Hucitec, 1994.

BEJARANO, J. El consumo de drogas como problema de saúde pública: desafíos para la investigación y la formulación de políticas. In: Briceño-León, R.; Minayo, M.C.S.; Coimbra Jr., C.E.A. (Org.). Salud y equidad: una mirada desde las ciencias sociales. Rio de Janeiro: Fiocruz, 2000.

BERQUÓ, E. (Org). Jovens acontecendo na trilha das politicas públicas. Brasília, DF: CNPD, 1998. v.1-2. 
BLANCHET, A.; GOTMAN, A. L'enquête et ses méthodes: l'entretien. Paris: Nathan, 1992.

BORGES, S.N. Metamorfoses do corpo: uma pedagogia freudiana. Rio de Janeiro: Fiocruz, 1996.

BRASIL. Ministério da Saúde. Sexualidade, prevenção das DST/AIDS e uso indevido de drogas: diretrizes para o trabalho com crianças e adolescentes. Brasília, DF, 1999.

BROOK, J.S.; BROOK, D.W.; DE LA ROSA, M.; DUQUE, L.F.; RODRIGUEZ, E.; MONTOYA, I. D.; WHITEMAN, M. Pathways to marijuana use among adolescents: cultural/ecological, family, peer, and personality influences. Journal of the American Academy of Child and Adolescent Psychiatry, Philadelphia, v. 37, n. 7, p. 759-766, 1998.

BUCHER, R. Drogas e drogadição no Brasil. Porto Alegre: Artes Médicas, 1992.

CAMARGO JUNIOR, K. Políticas públicas e prevenção em HIV/AIDS. In: Parker, R.; Galvão, J.; Bresson, M. (Org.). Saúde, desenvolvimento e política: respostas frente à AIDS no Brasil. São Paulo: Editora 34, 1999. p. 227-262.

CORTES, B. O jogo da onda: um convite ao diálogo. História, Ciências, Saúde, Rio de Janeiro, v. 5, n. 3, p. 762-765, 1999.

DAWSON, S; MANDERSON, L.; TALLO, V. The focus group manual: methods for social research in tropical diseases n. 1. (TDR/SER/ MRS/92.1). [s.1]: World Health Organization, 1992. p. 3-36.

DE WIT, D.J.; OFFORD, D.R.; WONG, M. Pattens of onset and cessation of drug use over the early part of the life course. Health Education \& Behavior, Thousand Oaks, v. 24, n. 6, p. 746-758, 1997.

DINIZ, S.; VILELLA, W. Interfaces entre os programas de DST/AIDS e saúde reprodutiva: o caso brasileiro. In: PARKer, R.; GALVÃo, J.; Bresson, M. (Org.). Saúde, desenvolvimento e política: respostas frente à AIDS no Brasil. São Paulo: Editora 34, 1999.

GILHAM, S.; SIVEWRIGHT, D. The impact of drug education and prevention programs disparity between impressionistic and empirical assessments. Evaluation Review, Bervely Hills, v. 21, n. 5, p. 589-613, 1997. 
GIROUX, H. Teoria crítica e resistência em educação. In: GadotTi, M. História das idéias pedagógicas. São Paulo: Ática, 1995. p. 319.

HEARST, N.; DIAS, P.; CALDEIRA, Z. Fatores de risco para o uso de drogas e infecção pelo HIV entre estudantes do $1^{\circ}$ e $2^{\circ}$ graus nas escolas da rede pública no Rio de Janeiro. In: Congresso Brasileiro de Prevenção em DST/Aids, 3., Rio de Janeiro, 1999. Anais... Brasília, DF: Ministério da Saúde, 1999.

INEM, C.; ACSELRAD, G. (Org.). Drogas: uma visão contemporânea. Rio de Janeiro: Imago, 1993.

KREFT, G.; BROWN, J. (Ed.). Zero effects of drug prevention programs: issues and solutions. Evaluation Review, Beverly Hills, v. 22, n. 1, p. 3-144, 1998.

L'ABBATE, S. Educação em saúde: uma nova abordagem. Cadernos de Saúde Pública, Rio de Janeiro, v. 10, n. 4, p. 481-490, 1994.

LEFÈVRE, F. Análise de cartazes sobre equistossomose elaborados por escolares. Revista Saúde Pública, São Paulo, v. 14, p. 369-403, 1980.

LOPES, M. Pesquisa em comunicação: formulação de um modelo metodológico. São Paulo: Loyola, 1994.

LYNSKEY, M.; WHITE, V.; HILL, D.; LETCHER, T.; HALL, W. Prevalence of illicit drug use among youth: results from the Australian school student's alcohol and drugs survey. Australian and New Zealand Journal of Public Health, Camberra, v. 23, n. 5, p. 519-24, 1999.

MARSHALL, C.; ROSSMAM, G. Recording, managing and analyzing data. In: Marshall, C.; Rossman, G. Designing qualitative research. 2. ed. Thousand Oaks: Sage, 1995. p. 109-119.

MELO, J. A. (Org.). Educação: razão e paixão. Rio de Janeiro: Panorama, ENSP, 1993.

MESQUITA, F.; BASTOS, F. (Org.). Drogas e AIDS: estratégias de redução de danos. São Paulo: Hucitec, 1994.

MONTEIRO, S.; REBELLO, S. Desenvolvimento e avaliação de jogos educativos no campo da prevenção do HIV/AIDS e do uso indevido de drogas. In: Acselrad, G. (Org.). Avessos do prazer: drogas, aids e direitos humanos. Rio de Janeiro: Fiocruz, 2000. p. 215-232. 
MONTEIRO, S.; REBELLO, S.; SCHALL, V. Jogo zig-zaids (jogo educativo). Rio de Janeiro: Salamandra/Fiocruz, 1991.

MONTEIRO, S.; REBELLO, S.; SCHALL, V. Jogando e aprendendo a viver: uma abordagem da AIDS e das drogas através de recursos educativos. In: Mesquita, F.; Bastos, F. (Org.). Drogas e AIDS: estratégias de redução de danos. São Paulo: Hucitec, 1994. p. 133-146.

MONTEIRO, S.; VARGAS E.; CRUZ, M. Educação, comunicação e tecnologia educacional: aproximações com o campo da saúde. Trabalho apresentado na 24a Reuniāo Anual da ANPED, Caxambu, 2001. Disponível em: <www.anped.org.br/24/T1652012012006.doc> Acesso em: maio 2003.

MOON, D.G.; HECHT, M.L.; JACKSON, K.M.; SPELLERS, R.E. Ethnic and gender differences and similarities in adolescent drug use and refusals of druf offers. Substance Use \& Misuse, New York, v. 34, n. 8, p. 1059-83, 1999.

ODGERS, P.; HOUGHTON, S.; DOUGLAS, G. The prevalence and frequency of drug use among Western Australian metropolitan high school students. Addictive Behaviors, Oxford, v. 22, n. 3, p. 315-25, 1997.

OLIVEIRA, M.W. Gravidez na adolescência: dimensões do problema. Cadernos Cedes, Campinas, v. 19, n. 45, jul. 1998.

OSHIRO, J. Educação para saúde nas instituições de saúde pública. 1988. Dissertação (Mestrado em Saúde Coletiva) - Pontifícia Universidade Católica de São Paulo, São Paulo.

PARKER, R; HERDT, G.; CARBALLO, M. Sexual culture, HIV transmission and AIDS research. Journal of Sex Research, Mount Vernon, v. 28, n. 1, p. 77-98, 1991.

REBELLO, S.; MONTEIRO, S. Jogo onda: entre na onda da saúde (jogo educativo). Rio de Janeiro: Fiocruz, 1998.

REBELLO, S.; MONTEIRO, S.; VARGAS, E.. A visão de escolares sobre drogas no uso de um jogo educativo. Interface: comunicação, saúde e educação, Botucatu, v. 5, n. 8, 2001.

RIBINIK, M.L. Tecnologia educacional: classificação das diferentes definições com base em revisão bibliográfica. Disponível em: <www.ensp.fiocruz.br/sde/sete/index.html.> Acesso em: abril de 2001. 
ROCCO, J.J. Sexualidade e mudanças de comportamentos: uma estratégia lúdica de prevenção da AIDS. In: HeIlborN, M.L (Org.). Sexualidade: o olhar das ciências sociais. Rio de Janeiro: Zahar, 1999. p. 175-199.

SÁ, D.T.; SIQUEIRA, V.H.F.; MARTELETO, M.A. Demanda e clientela multiprofissional para um mestrado em tecnologia educacional nas ciências da saúde. Cadernos de Saúde Pública, Rio de Janeiro, v. 15, supl. 2, p. 44-53, 1999.

SCHALL, V.; MONTEIRO, S.; REBELLO, S.; TORRES, M. Evaluation of the zig-zaids game: an entertaining educacional tool for HIV/AIDS prevention. Cadernos de Saúde Pública, Rio de Janeiro, v. 15, supl. 2, p. 107-119, 1999.

SCHOR, N.; MOTA, M.S.; CASTELO BRANCO, V. (Org.). Cadernos juventude, saúde e desenvolvimento. Brasília, DF: Ministério da Saúde, Secretaria de Políticas de Saúde, 1999.

SIQUEIRA, V.H.F. O vídeo educativo produzido pelo Núcleo de Tecnologia Educacional para a Saúde/UfrJ: uma visão crítica. Revista Brasileira de Educação Médica, Rio de Janeiro, v. 22, 1998.

SOARES, C. Adolescentes, drogas e AIDS: avaliando a prevenção e levantando necessidades. 1997. 284f. Tese (Doutorado em Educação) Faculdade de Educação, Universidade de São Paulo, São Paulo.

SOUZA, E.S. Meninos e meninas: expectativas corporais e implicações na educação física escolar. Cadernos Cedes, Campinas, v. 19, n. 48, ago. 1999.

STONE, V.I. Avaliação de materiais instrucionais. In: STONE, V.I. Questôes de avaliação. Rio de Janeiro: ABT, 1981. (Estudos e pesquisas, 20).

STOLZ, E.N.. Enfoques sobre Educação e Saúde. In: VALLA, V.V.; Stoltz, E.N. (Org.). Participação popular, educação e saúde: teoria e prática. Rio de Janeiro: Relume-Dumará, 1993.

TIBA, I. Respostas sobre drogas. São Paulo: Scipioni, 1998.

VARGAS, E.P.; SIQUEIRA, V.H.F. Sexualidade e corpo: o olhar do sujeito através das imagens em vídeo. Cadernos de Saúde Pública, Rio de Janeiro, v. 15, supl. 2, p. 69-83, 1999. 
VARGAS, E.V. Os corpos intensivos: sobre o estatuto social do consumo de drogas legais e ilegais. In: Duarte, L.F.; Leal, O.F. (Org.). Doença, sofrimento, perturbação: perspectivas etnográficas. Rio de Janeiro: Fiocruz, 1998. p. 121-136.

VARGAS, E.; REBELLO, S.; SILVA, F.; MONTEIRO, S. Caracterização da produção de recursos educativos sobre DST/AIDS e temas afins: um estudo exploratório. In: FORUM, 1., e Conferência de Cooperação Técnica Horizontal da América Latina e do Caribe em HIV/AIDS e DST, 2., 2000. Anais... [s.n.t.]. v.2.

VASCONCELOS, E. M. Educação popular e a atenção à saúde da família. Rio de Janeiro: Hucitec, 1999. 